\title{
Pre-registration nursing student's quality of practice learning: Clinical learning environment inventory (actual) questionnaire
}

Shivers, E., Hasson, F., \& Slater, P. (2017). Pre-registration nursing student's quality of practice learning: Clinical learning environment inventory (actual) questionnaire. Nurse Education Today, 55, 58-64. https://doi.org/10.1016/j.nedt.2017.05.004

Link to publication record in Ulster University Research Portal

\section{Published in:}

Nurse Education Today

Publication Status:

Published (in print/issue): 01/08/2017

DOI:

10.1016/j.nedt.2017.05.004

\section{Document Version}

Author Accepted version

\section{General rights}

Copyright for the publications made accessible via Ulster University's Research Portal is retained by the author(s) and / or other copyright owners and it is a condition of accessing these publications that users recognise and abide by the legal requirements associated with these rights.

\section{Take down policy}

The Research Portal is Ulster University's institutional repository that provides access to Ulster's research outputs. Every effort has been made to ensure that content in the Research Portal does not infringe any person's rights, or applicable UK laws. If you discover content in the Research Portal that you believe breaches copyright or violates any law, please contact pure-support@ulster.ac.uk. 
Education Today

Elsevier Editorial System(tm) for Nurse

Manuscript Draft

Manuscript Number: NET-D-16-00577R3

Title: PRE-REGISTRATION NURSING STUDENT'S QUALITY OF PRACTICE LEARNING: CLINICAL LEARNING ENVIRONMENT INVENTORY (ACTUAL) QUESTIONNAIRE

Article Type: Research Paper

Section/Category: Research articles

Keywords: Nursing students, Pre-Registration, Clinical learning environment, Perception, Placement, Clinical learning environment inventory.

Corresponding Author: Dr. Felicity Hasson, Ph.D

Corresponding Author's Institution: Ulster University

First Author: Eleanor Shivers, BSc Hon's, PG Dip Mang, PG Dip Spec, MSc

Order of Authors: Eleanor Shivers, BSc Hon's, PG Dip Mang, PG Dip Spec, MSC ; Felicity Hasson, Ph.D; Paul Slater, BSC, MSC, PhD, Pg. CHEP

Manuscript Region of Origin: UNITED KINGDOM

Abstract: Background: Clinical learning is a vital component of nurse education and assessing student's experiences can provide useful insights for development. Whilst most research in this area has focused on the acute setting little attention has been given to all pre-registration nurses' experience across the clinical placements arenas. objectives: To examine of pre-registration nursing students (first, second and third year) assessment of their actual experiences of their most recent clinical learning clinical learning experience.

Design: A cross sectional survey involving a descriptive online anonymous questionnaire based on the clinical learning environment inventory tool. Settings: One higher education institution in the United Kingdom Participants: Nursing students $(n=147)$ enrolled in an undergraduate nursing degree.

Methods: This questionnaire included demographic questions and the Clinical Learning Environment Inventory (CLEI) a 42 item tool measuring student's satisfaction with clinical placement. SPPS version 22 was employed to analyse data with descriptive and inferential statistics. Results: Overall students were satisfied with their clinical learning experience across all placement areas. This was linked to the 6 constructs of the clinical learning environment inventory; personalization, innovation, individualization, task orientation, involvement, satisfaction. Significant differences in student experience were noted between age groups and student year but there was no difference noted between placement type, age and gender.

Conclusions: Nursing students had a positive perception of their clinical learning experience, although there remains room for improvement. Enabling a greater understanding of students perspective on the quality of clinical education is important for nursing education and future research. 

Nurse Education Today

Elsevier Inc.

1600 John F. Kennedy Boulevard, Suite 1800

Philadelphia, PA 19103-2899

USA

Dear Sir/ Madam,

Ms. Ref. No.: NET-D-16-00577R2

Title: PRE-REGISTRATION NURSING STUDENT'S QUALITY OF PRACTICE LEARNING: CLINICAL LEARNING ENVIRONMENT INVENTORY (ACTUAL) QUESTIONNAIRE

Thank you for the opportunity to strengthen this paper again and for the valuable reviewers' comments. Please find attached two revised copies (one red font and the other plain) of the above manuscript, for consideration of publication within the Nurse Education Today.

This work has not been published elsewhere and is not under consideration for publication elsewhere. All authors meet the criteria for authorship in the journal and this all authors have contributed equally to the development of this article. In addition the manuscript has been read and approved by all the authors. No conflicts of interest exist for any authors.

If you require any further information please do not hesitate to contact me on email: f.hasson@ulster.ac.uk

Yours faithfully

$$
\text { Jelicity Hassen }
$$

Dr Felicity Hasson, Senior Lecturer,

University of Ulster, Institute of Nursing Research and School of Nursing, Newtownabbey, Shore Road, BT37 0QB, Co. Antrim

Northern Ireland Telephone: 02890366895 Fax Number 02890368202 ,

Email: f.hasson@ulster.ac.uk 
RESPONSE TO REVIEWERS

Ms. Ref. No.: NET-D-16-00577R2

Title: PRE-REGISTRATION NURSING STUDENT'S QUALITY OF PRACTICE LEARNING: CLINICAL LEARNING ENVIRONMENT INVENTORY (ACTUAL) QUESTIONNAIRE Nurse Education Today

\section{REVIEWER \#1:}

\begin{tabular}{|c|c|c|c|}
\hline Reviewer Comment & $\begin{array}{l}\text { Author Response to } \\
\text { Comment }\end{array}$ & Changes made to article & Page No. \\
\hline $\begin{array}{l}\text { We note that the } \\
\text { paper is now sitting at } \\
6204 \text { words and there } \\
\text { is some repetition } \\
\text { between the results } \\
\text { and } \\
\text { discussion/conclusion } \\
\text { and tables. There is } \\
\text { some flexibility in word } \\
\text { count, but we would } \\
\text { appreciate if you could } \\
\text { edit the manuscript to } \\
\text { try and bring it closer } \\
\text { to the word count } \\
\text { specified in the author } \\
\text { guidelines (5,000 } \\
\text { words max). }\end{array}$ & $\begin{array}{l}\text { The authors have } \\
\text { reduced the word } \\
\text { count to } 5422 \\
\text { (including references } \\
\text { and abstract) }\end{array}$ & & \\
\hline $\begin{array}{l}\text { We had to reread lots } \\
\text { of sentences because } \\
\text { there is a lack of } \\
\text { appropriate } \\
\text { punctuation in a } \\
\text { number of sentences. } \\
\text { It is often helpful to } \\
\text { get someone else to } \\
\text { read the manuscript. }\end{array}$ & $\begin{array}{l}\text { The authors have } \\
\text { responded and have } \\
\text { addressed these issues } \\
\text { throughout the paper. }\end{array}$ & & \\
\hline $\begin{array}{l}\text { The European Directive } \\
\text { (2005) for the training } \\
\text { of general nurses - } \\
\text { should be education }\end{array}$ & Inserted education & $\begin{array}{l}\text { The European Directive (2005) for } \\
\text { the education of general nurses } \\
\text { requires } 4,600 \text { hours of } \\
\text { theoretical and clinical } \\
\text { components, with at least half of } \\
\text { this time spent in the clinical } \\
\text { setting. }\end{array}$ & P1 \\
\hline $\begin{array}{l}\text { Page one - it is } \\
\text { important to that such }\end{array}$ & Deleted 'to' & $\begin{array}{l}\text { Given the acute shortage of } \\
\text { clinical placement positions, it is } \\
\text { important that such } \\
\text { environments are "suited to }\end{array}$ & P1 \\
\hline
\end{tabular}




\begin{tabular}{|c|c|c|c|}
\hline & & $\begin{array}{l}\text { students' perceptions and } \\
\text { expectations" (Brown et al., 2011, } \\
\text { p e22). }\end{array}$ & \\
\hline $\begin{array}{l}\text { plural challenging } \\
\text { opportunities for } \\
\text { students to be able to } \\
\text { learn critical - plural }\end{array}$ & Re-worded & $\begin{array}{l}\text { Previous research has consistently } \\
\text { reported that students perceive } \\
\text { personalisation to be of primary } \\
\text { importance (Siggins Miller } \\
\text { Consultants, 2012). }\end{array}$ & P3 \\
\hline $\begin{array}{l}\text { - plural challenging } \\
\text { opportunities for } \\
\text { students to be able to } \\
\text { learn critical - plural }\end{array}$ & Reworded & $\begin{array}{l}\text { However, reports that students } \\
\text { are doing routine and non-nursing } \\
\text { duties (Hasson, 2012) suggest } \\
\text { that some placement areas may } \\
\text { limit access to challenging } \\
\text { learning opportunities for } \\
\text { students, stifling occasions to } \\
\text { learn critical and clinical } \\
\text { judgement skills (Kaphagawani } \\
\text { and Useh, 2013). }\end{array}$ & P3-4 \\
\hline $\begin{array}{l}\text { Check et al. for full } \\
\text { stops throughout }\end{array}$ & $\begin{array}{l}\text { All et al's have been } \\
\text { changed to et al. } \\
\text { throughout }\end{array}$ & & \\
\hline $\begin{array}{l}\text { Throughout - data is } \\
\text { plural so data were, } \\
\text { data were checked etc }\end{array}$ & Reworded & $\begin{array}{l}\text { Data were checked for missing } \\
\text { responses and central tendencies } \\
\text { calculated. }\end{array}$ & P6 \\
\hline $\begin{array}{l}\text { Whole sentence needs } \\
\text { a rewrite - Where } \\
\text { significant was } \\
\text { identified, differences } \\
\text { in mean scores were } \\
\text { examined using } \\
\text { appropriate descriptive } \\
\text { and inferential } \\
\text { statistics were } \\
\text { computed to describe } \\
\text { and summarise the } \\
\text { survey data for each } \\
\text { cohort and placement } \\
\text { area. }\end{array}$ & Reworded & $\begin{array}{l}\text { Statistical significant results mean } \\
\text { differences were examined, to } \\
\text { describe the survey data for each } \\
\text { cohort and placement area. }\end{array}$ & P6 \\
\hline $\begin{array}{l}\text { Something like - From } \\
\text { a potential population. } \\
\text { A potential population } \\
\text { of } 633 \text { nursing } \\
\text { students, }\end{array}$ & Changed & $\begin{array}{l}\text { From a potential population of } \\
633 \text { nursing students, } 152 \\
\text { completed the CLEI } \\
\text { questionnaire, giving a response } \\
\text { rate of } 24 \% .\end{array}$ & P6 \\
\hline $\begin{array}{l}2 \text { constructs achieving } \\
\text { score in the banding - } \\
\text { plural scores }\end{array}$ & Changed & $\begin{array}{l}\text { Cronbach Alpha scores show that } \\
\text { four of the six constructs were } \\
\text { above the acceptable threshold of }\end{array}$ & P7 \\
\hline
\end{tabular}




\begin{tabular}{|l|l|l|l|}
\hline & & $\begin{array}{l}0.7 ; \text { with two constructs achieving } \\
\text { scores in the banding 0.6-0.7. }\end{array}$ & \\
\hline $\begin{array}{l}\text { Full stop and then } \\
\text { (table 3). A maximum } \\
\text { score of 4 was } \\
\text { possible. }\end{array}$ & Reworded & $\begin{array}{l}\text { With a maximum score of four } \\
\text { was possible, the mean score } \\
\text { ranged from 2.48-3.20 indicating } \\
\text { a positive but not strongly } \\
\text { positive view (table 3). }\end{array}$ & P7 \\
\hline $\begin{array}{l}\text { The innovation sub } \\
\text { scale gained the lowest } \\
\text { mean score }\end{array}$ & Reworded & $\begin{array}{l}\text { The innovation sub scale gained } \\
\text { the lowest mean score 2.48, } \\
\text { highlighting a need for } \\
\text { improvement in this area. }\end{array}$ & P7 \\
\hline $\begin{array}{l}\text { Conclusion - } \\
\text { importance of } \\
\text { personalisatiion (typo) }\end{array}$ & Reworded & $\begin{array}{l}\text { ndings confirm the importance of } \\
\text { personalisation and sense of } \\
\text { belonging and acceptance for } \\
\text { nursing students to be a key } \\
\text { factor in the clinical learning } \\
\text { environment. }\end{array}$ & P14 \\
\hline
\end{tabular}


TITLE: PRE-REGISTRATION NURSING STUDENT'S QUALITY OF PRACTICE

LEARNING: CLINICAL LEARNING ENVIRONMENT INVENTORY (ACTUAL) QUESTIONNAIRE

WORD COUNT: 5422 (including abstract and references)

\section{AUTHORS:}

Eleanor Shivers, BSc Hon's, PG Dip Mang, PG Dip Spec, MSc Student, Institute of Nursing and Health Research Ulster University, Shore Road, Newtownabbey, Co. Antrim BT37 0QB, Northern Ireland. Email: mcconvilleh@aol.com

* Dr Felicity Hasson, BA (Hons), MSc, PG Dip, PhD, Pg. CHEP, Senior Lecturer, Institute of Nursing \& Health Research, Ulster University, Shore Road, Newtownabbey, Co. Antrim BT37 0QB, Northern Ireland. Telephone: 0044 (0) 2890366895 Fax: 0044 (0)28 9036 8202 Email: f.hasson@ulster.ac.uk

Dr Paul Slater BSc, MSc, PhD, Pg. CHEP, Lecturer in Statistics, Institute of Nursing \& Health Research, School of Nursing and Health Sciences, Ulster University, Shore Road, Newtownabbey, Co. Antrim BT37 0QB, Northern Ireland. Telephone: 0044 (0) 289036 6400 Fax: 0044 (0)28 90368202 Email: pf.slater@ulster.ac.uk

*Corresponding author

\section{Acknowledgements}

We acknowledge and thank the nursing students who participated in this survey.

Funding: This research did not receive any specific grant from funding agencies in the public, commercial, or not-for-profit sectors. 



\section{INTRODUCTION}

Historically and legally, clinical teaching is one of the major components of nursing worldwide (Siggins Miller Consultants, 2012). As well as clinical skill development, practice in a clinical setting also enables socialization into the professional role (Thomas et al., 2015). The European Directive (2005) for the education of general nurses requires 4,600 hours of theoretical and clinical components, with at least half of this time spent in the clinical setting. In the United Kingdom, 50\% of nurse education is undertaken in the clinical arena, in a range of settings (Murphy et al., 2012) including community and acute. A raft of studies have highlighted that clinical experience influences students attitudes towards that clinical setting (Bjørk et al., 2014, Happel and Gaskin, 2013, Awuah-Peasah et al., 2013 Happel and Platania-Phung, 2012). To the extent that it can sway where they are likely to work once graduated (Boyd-Turner et al., 2016, McKenna et al., 2010). Therefore, it is vital that practice learning experience is of high quality and valued by pre-registration nurses in order to enhance student's learning outcomes.

Yet questions regarding the quality of the placement have arisen (Willis Commission, 2012, Royal College of Nursing, 2008) with evidence suggesting that students do not believe that all clinical learning environments are conducive to learning (Callaghan, 2011, Perli and Brugnolli, 2009). Given the acute shortage of clinical placement positions, it is important that such environments are "suited to students' perceptions and expectations" (Brown et al., 2011, p e22). However the majority of research from the student perspective of placement has focused on acute sector placements (Bjørk et al., 2014). The purpose of this study is to assess students' views and perceptions of their most recent clinical learning environment, including hospital, community, surgical and other (nursing home). 


\section{BACKGROUND/ LITERATURE}

Clinical nurse education is located within a range of settings, each presenting its own complex social environment. In each setting, the student nurse has a dual role of learner and active involvement, contributing to patient care (Allan et al., 2011). However, clinical learning occurs in an environment designed for clinical services rather than education (Henning et al., 2011). Therefore, a lack of control of the environment may influence the quality of the student learning. Nevertheless, research has identified that sociocultural characteristics of a learning environment can influence students' experiences (Moos, 1974). In reviewing clinical education experiences of nurses, Chan (2003) outlined the six psychosocial aspects students identify as important in the clinical learning environment (see table 1).

\section{Insert table 1 here}

The six psycho-social aspects form the basis of the Clinical Learning Environment Inventory (CLEI) (Chan, 2003), which is one of the most commonly used instruments used to measure students' perceptions (Bjørk et al., 2014). The tool consists of two scales (Actual and Expected). The actual scale measures the actual learning environment, whilst the expected assesses what the students would ideally like in the clinical environment. The application of the actual tool has mostly been used to access students' views of hospital placements (Bigdeli et al., 2015, Poon 2014, Papathanasiou et al., 2014, Perli and Brugnoilli, 2009, Midgley 2006, Henderson et al., 2006). However, a growing body of research has started to explore other clinical settings such as nursing homes (Berntsen and Bjørk, 2010), mental health facilities (Saarikoski et al., 2006) and primary care practices (McInnes et al., 2015). The tool has been found to be homogeneous and its validity established in several countries worldwide including Greece (Papathanasiou et al., 2014), Italy (Serena and Anna 2009), and Australia 
(Chan, 2003). In addition, Chan (2003) and colleagues (2007) reported good psychometric properties of the tool with established internal reliability (Chan, 2003, Perli and Brugnolli, 2009, Bjork et al., 2014) and discriminant validity (Chan, 2003, Chan and Ip, 2007). For example, Chan (2007) reported the Cronbach alpha coefficients ranging from 0.73-0.84 and 0.66-0.80 respectively for the actual and expected scales. With regards to face validity, items of the CLEI tool were derived from the literature, modified classroom environment tool and a panel of experts. This is an accepted approach to computing the face validity index (Polit and Beck, 2006).

Previous research has consistently reported that students perceive personalisation to be of primary importance (Siggins Miller Consultants, 2012). Such findings are common themes across health setting, discipline and country (Bigdeli et al,. 2015; Papathanasiou et al., 2014, Rodger et al., 2011, Brown et al., 2011, Smedley and Morey, 2010, Ralph et al., 2009). Nursing research supports this, for example, a number of authors report that good communication and collaboration between student's clinical tutors and/or practitioners (Courtney-Pratt et al., 2012, Brown et al., 2011, Smedley and Morey, 2010), involvement in practice (Chuan and Barnett, 2012), and feeling part of the team (Midgley, 2006, Papp et al., 2003), can affect the acquisition of skills, knowledge and professionalism. However, research suggests that access to qualified supervision and support is unstandardized across clinical environments, such as nursing homes (Harrington et al., 2012).

Results from previous CLEI studies indicate that nursing students are involved in the accomplishment of tasks, albeit at varying levels (Smedley and Morey, 2009, Perli and Brugnolli, 2009, Henderson et al., 2006). However, reports that students are doing routine and non-nursing duties (Hasson, 2012) suggest that some placement areas may limit access to 
challenging learning opportunities for students, stifling occasions to learn critical and clinical judgement skills (Kaphagawani and Useh, 2013).

Concepts such as innovation have not featured strongly in some CELI studies (Papathanasiou et al., 2014, Smedley and Morey, 2009, Chan and Ip, 2007, Midgley, 2006, Henderson et al., 2006), and a number of studies have reported individualisation to have low scores (Berntsen and Bjørk, 2010, Perli and Brugnolli, 2009, Ip and Chan, 2005). However, Bjørk et al. (2014) reported that mental health care students scored this concept as high, attributing this to characteristics of the placement setting.

Students' level of satisfaction score with clinical placement reportedly varies. In a UK study, Murphy et al. (2012) compared students' level of satisfaction across hospital and community placement settings and reported that district nursing was the best liked placement. Whilst in a Norwegian study, Skaalvik et al. (2011) reported that students assessed nursing home placements negatively. However, satisfaction score can be influenced by a number of factors, such as level of engagement, feeling part of a team, and being involved in well-organised activities (Lamont et al., 2015, Levett-Jones et al., 2007). Two Iranian studies concluded that satisfaction was not considered in clinical education environments (Bigdeli et al., 2015; Moattari and Ramezani, 2009), despite Chan and Ip (2007) viewing it as an education outcome requiring the attention of nursing authorities and policy makers.

\section{METHODS}

This was a descriptive, cross-sectional online survey. With permission of the author (Chan, 2002), the actual CLEI questionnaire was used. It consists of 40 items grouped into six construct scales with each scale consisting of seven Likert (four-point) scale type questions 
(1-4, 1 being strongly negative and 4 being strongly positive). Two of the questions were excluded as they were felt to be non-applicable to the areas of clinical learning. The validity of the modified sub scale was confirmed prior to full analysis. A pilot study was conducted with 51 third year pre-registration nursing students (adult branch), not included in the main study, and reviewed by a panel of education experts to ensure the appropriateness of wording and understanding. This process contributed to the reliability and validity of the questionnaire and helped to ensure clarity and ease of administration (Boynton, 2004).

In addition to the CLEI tool, a demographics section was added to the questionnaire, to enable baseline characteristics of respondents to be summarised. Cronbach alpha coefficients of CLEI scale have ranged from 0.73 to 0.84 (Chan, 2003). These Cronbach alpha coefficients confirmed reliability however Chan and Ip (2007) reported less reliable Cronbachs alpha of $0.5-0.8$, following modification of the instrument. The Cronbach alpha coefficients for this study for each scale ranged from 0.61-0.90, which confirm a very satisfactory level of scale reliability ( Tavakol and Dennick, 2011).

\section{Setting and Sample}

All adult and mental health nursing students enrolled on the BSc (Hons) programme ( $\mathrm{n}=633$ ) from one higher educational institution in the United Kingdom were surveyed during March 2014. All nursing students had experience of clinical placement. The range of placement areas include, Community, Hospital, Learning Disability and Mental Health, Community Public Health, Critical care, Perioperative care, Public Health, Continuing Care and Chronic Illness, Multi-disciplinary Team Assessment and Rehabilitation, and Management.

\section{Data collection}


Full ethical approval was obtained prior to data collection, from the host educational institution. An invitation email, with a link to a participant information sheet and the questionnaire, was administered to all first, second and final year nursing students. To encourage survey completion, reminder emails were issued at weeks one and two, and oral presentations about the research given to each year group (by author EMcC not associated with any teaching responsibilities). Return of the questionnaire implied consent and potential respondents were guaranteed anonymity.

\section{Data analysis}

Results were collected using QUALTRICS and analysed using Statistical Package for Social Sciences (SPSS) Statistics Software (Version 21). Data were checked for missing responses and central tendencies calculated. Normality and distribution was determined through the appropriate statistical test. Multiple regression analysis was used to identify independent variables where further statistical examinations were required, thereby reducing the potential of multiplicity. Statistical significant results mean differences were examined, to describe the survey data for each cohort and placement area.

\section{DATA/RESULTS}

From a potential population of 633 nursing students, 152 completed the CLEI questionnaire, giving a response rate of $24 \%$. Data cleaning techniques identified five participants had not completed more than $10 \%$ of the questionnaire, leaving 147 useable data sets for analysis. Based on the Raosoft sample calculator, with a population of $633,95 \%$ confidence level; and a response distribution of $50 \%$ a response rate of $n=147$ produced a margin of error of $7.1 \%$. Demographic information $(n=147)$, revealed that the highest proportion of respondents were 
female, aged 18-24 and third year students in the adult branch, who completed their practice learning experience in the hospital setting. (See table 2).

\section{Insert table 2 here}

\section{Measures of distribution}

Measures of skewness and kurtosis are within the acceptable range, justifying the use of parametric statistics tests throughout (see table 3). Internal consistency of the items was measured by using Cronbach's alpha coefficients. Cronbach Alpha scores show that four of the six constructs were above the acceptable threshold of 0.7 ; with two constructs achieving scores in the banding 0.6-0.7. Item deletion failed to correct for low Alpha scores. Psychological constructs values below 0.7 have been attributed to the diversity of the constructs being measured (Field, 2006).

\section{Insert table 3 here}

Students were moderately satisfied with their clinical learning experience. With a maximum score of four was possible, the mean score ranged from 2.48-3.20 indicating a positive but not strongly positive view (table 3). The subscale 'Satisfaction' gained the highest mean score 3.20, indicating a more positive perception. The innovation sub scale gained the lowest mean score 2.48 , highlighting a need for improvement in this area.

The majority of the CLEI frequency scores were positively scored (see table 4). The highest scored item was 'Students pay attention to what others are saying'. Within the CLEI 'others' are not specified, however, this could be mentors, preceptors or academic members of staff. 
Other high score items include 'Students put effort into what they do on their practice learning experience', and 'This practice learning experience is a waste of time'.

Not all students felt positively about the experience. Table 4 shows that almost half $(46.3 \%)$ of participants felt 'New ideas were seldom tried out in this area', and $12.9 \%$ disagreed that 'After the shift the student has a sense of satisfaction'. Scores regarding the mentor's role were also negatively scored for example, 'The Mentor is unfriendly and inconsiderate towards students', 'Mentor is not interested in student problems' and 'Mentors dominates briefing sessions/ review of progress'.

\section{Insert table 4 here}

The CLEI works on six construct factors, factor items were aggregated to generate factor scores. Examination of a correlation matrix show high positive correlations of all six factors, with 12 of 15 relationship scored between $.05-071$, at a statistically significant level $(\mathrm{p}=0.01$, 1-tailed). One-way ANOVA was undertaken of each of the six scales of the tool across each clinical placement setting in order to identify differences in student experiences. Differences across subgroups (i.e. student gender, and branch), were tested with T-tests and differences in age group or student year, and clinical placement were tested using one-way ANOVA (see table 5).

\section{Insert table 5 here}

Statistically significant difference noted on 'Personalisation' $(F(2,146)=3.667, p=0.028)$ across placement settings. Post hoc Scheffe analysis indicated the differences were between 
hospital and community placements $(\mathrm{p}=0.033)$ where community placement students had significantly higher scores (see table 4). No statistical differences were noted according to gender of students due to small number of male students $(n=11)$ therefore limiting comparisons.

There was a statistically significant difference in the satisfaction sub scale for the student year groups $(\mathrm{F}(2,144)=4.102, \mathrm{p}=0.019)$. Post hoc comparisons Scheffe test indicated the mean score for Year $1(\mathrm{M}=3.40, \mathrm{SD}=0.42)$ did differ significantly from Year $2(\mathrm{M}=3.06$, $\mathrm{SD}=0.71)$ and Year $3(\mathrm{M}=3.18, \mathrm{SD}=0.48)$, highlighted with a $\mathrm{p}$ value $\mathrm{p}=0.22$. Assumption of homogeneity of variance was violated for the mean 'Satisfaction' sub scale score, so Robust Tests of Equality of means was examined. Brown -Forsythe and Welch show (Sig) P value of 0.01 and 0.03 respectively indicating that satisfaction rating is affected by year. Year one to year three scores gradually decrease across years on sub scales including personalisation, involvement and task orientation. When comparing across different years, year one recorded a higher score. These indicate their experience of these constructs of their clinical learning experience are more positive than second year and second year students have a more positive experience than third year students.

Statistically significant differences were noted across nursing courses on one construct 'Individualisation' where Mental Health nurses scored the construct higher than Adult Nurses $(\mathrm{T}(144)=-2.144, \mathrm{p}=0.034) . \quad$ Examinations of differences of perceptions between age groups were conducted using One-way ANOVA with students categorised into four groups; 18-24, 25-34, 35-44, 45-54. Means and standard deviation are detailed (Table 5). A statistical difference was noted and showed a small difference between age groups in the 'Involvement' sub scale with a p-value of 0.01 , however, the other five sub scale scores were 
not statistically significant. Post-hoc comparisons using Scheffe test indicated a significant difference for the mean score for age groups 18-24 and 35-44.

The items of the CLEI were individually analysed according to clinical placement (see table 6). Of the 42 items, eight were identified as having statistically significant differences and post hoc tests indicate where these differences existed. Table 6 shows the level of statistical significance and examination of the pattern of responses show that Community scored the items higher in all 8 items and generally surgical scored it lowest. Post hoc analysis report significant differences between community and hospital scores on items 2, 3, 4, 5, 6, 7; and community and surgical on items 1 and 7.

\section{Insert table 6 here}

\section{DICSUSSION}

The actual experiences of pre-registration nursing students of their most recent practice learning experience were examined and compared to their perceptions across student year groups, demographics and placement type. Findings indicate that pre-registration students had different perceptions of their clinical learning experience in the clinical setting. In general, students were satisfied with their clinical learning experience, with a positive but not strongly positive view.

Based on Chan's (2003) six psycho-social aspects, satisfaction was rated the highest, followed by personalization and reflective of previous research (Midgley, 2006, Chan, 2002). It seems that students are looking for support and acknowledgement of their progress, and rate this as a top priority in their clinical learning experience (Bernsten and Bjørk, 2010). 
The importance of human relationships in clinical learning is a concurrent theme in the literature (Papathanasiou et al., 2014, Henderson et al., 2006, Chan, 2002), which is unsurprising given that supportive relationships can trigger internalization of the professional role (Killam et al., 2013). This is why establishing effective working relations is the first outcome for a stage two mentor (NMC, 2008).

However this study's results are slightly different in that "satisfaction" was the highest score rather than "personalisation" as in previous studies (Papathanasiou et al., 2014, Berntsen and Bjørk , 2010, Perli and Brugnolli, 2009, Smedley and Morey, 2009, Chan and Ip, 2007, Ip and Chan, 2005). This suggests that students generally experienced a less than positive clinical placement experience, especially related innovation and individualization issues. These issues require careful consideration for future placement of students.

The innovation sub scale gained the lowest mean score, reflecting previous research (Bernsten and Bjørk, 2010, Chan and Ip, 2007, Midgley, 2006). Such findings may be attributed to the perceived routine nature of care and indicate mentors may not have fulfilled this part of their role. This is despite research recommending that mentors spend more time ensuring a creative and innovative experience which should be provided through academicpractice agreements (Niederhauser et al., 2012, Chan, 2002). However the realities of staff shortages, economic cuts, and increasing clinical demands, may hamper the ability to provide such experiences and new ways of working.

Results from the "Satisfaction" sub scale in this study were found to be positively associated with other sub scales in the CLEI. Chan (2002) recommends the use of the sub scale 'satisfaction' as an outcome measure for the overall perception of learning environment. This 
has been examined in previous studies and used as an overall indicator of the pre-registration nurse's experience (Papathanasious et al., 201,; Brown et al., 2011, Berntsen and Bjørk, 2010, Chan and Ip, 2007). Findings in this study suggest that all five sub scales were significant predictors and account for $55 \%$ of the total variance. This appears to relate strongly to overall satisfaction of clinical learning experience. Papathanasiou et al. (2014) adds that effective participation of students leads to positive experience in the working environment. Involvement, however, requires the student to be able to take part and work as part of the team, enabling students to carry out tasks and develop skills and confidence with practice. However, many students perceive their learning experience as anxiety provoking and it has been reported by Chan (2002) that this feeling often leaves students when they are busy with placement activities.

Reflective of Bjørk et al. (2014), work differences between placement groups were not highly significant. There are comparisons regarding the best type of clinical learning experience (Murphy et al., 2012), however, no overall significant difference were observed in this study. Differences between age groups (18-24 and 35-44), in the involvement sub scale were reported, which may be attributed to 18-24 age group still developing confidence and integration skills within a clinical setting. Whereas, the 35-44 age group involvement score may be underpinned by entering nurse education with prior work/ life experience (Hasson 2012), having greater motivation, and an overall maturity enabling them to deal with varied situations (Bjørk et al., 2014). Nursing educational literature suggests that consideration of the students individual learning styles should be considered in order to maximise the learning experience (Midgley, 2006). Smedley and Morey (2009) add that in nurse education, teaching styles rely on an adult learning approach, which may not be appropriate for the young adult learner (Abdollahimohammad and Ja'afar 2014, Smedley and Morey, 2009). 
These findings highlight the need to examine further the effect of student's age on the perceptions of their clinical learning experience.

CLEI scores indicate that satisfaction scores were affected by year. This is contrary to Ip and Chan's (2005) study which reported that year three and four had a more positive experience, and with O'Reilly Knapp's (1994) findings who reported there was no difference between age groups in overall satisfaction scores. It has been recognised that year one for nursing students is a transitional period and may be seen as a culture shock (Ip and Chan, 2005), therefore, additional effort may be made to provide these students with more preparation and greater support and encouragement. Years two and three may have developed a greater insight into the learning environment and what is expected from them and their mentors and may feel that this is not achieved.

The CELI, based on Moos' (1974) theoretical framework, emphasises the importance of relationships, personal, and system (maintenance and change) dimensions. Findings of this study suggest that each domain has a relative value of importance for the student nurse. The need to prepare students across each of these domains using innovative approaches to enhance perpetration for the reality of their role has been advocated (Neiderhauser et al., 2012). Central to this, is the development of academic-practice collaborations to reduce the theory practice gap, between learning and clinical realities. This may be achieved by adopting innovative placement allocations (Leigh et al., 2014) or positioning the academic lecturer in clinical practice (Leigh, 2014), to build upon personalisation and individualisation issues.

\section{Limitations}


This study has a number of strengths, for example, being based on a previous validated instrument, the inclusion of a diversity of student years, age groups and perspectives from multiple clinical sites. Several limitations must also be recognised. First, this study was undertaken within one higher educational institution, questioning generalization of the findings. Second, a low response rate was achieved from the overall study population, suggesting possible risk of bias. Nevertheless according to the literature, the overall response rate was high. Third, the cross-sectional design does not provide definite information about the cause-and-effect relationship. Finally, although the curricular for pre-registration nursing education in the United Kingdom is similar to other countries, differences regarding clinical placements and mentorships styles must also be considered.

\section{CONCLUSIONS}

The results show that pre-registration nursing students are positive about their perceptions of the clinical learning environment, however generally there is room for improvement. Students who scored a high level on the sub scale satisfaction also scored a high level on the other five sub scales namely, personalisation, involvement, task orientation, innovation and individualisation showing a strong association between these. Findings confirm the importance of personalisation and sense of belonging and acceptance for nursing students to be a key factor in the clinical learning environment. Further research exploring differing clinical learning environments is recommended. In addition it may also be useful to examine in detail why age and year affect perceptions of the clinical learning environment. Clinical placement experience is vital in the delivery of health education. Therefore, it is important to assess the students' experience to ensure the clinical learning experience meets their needs at every stage in their training, to enable the preparation and development of future nurses. 


\section{REFERENCES}

Abdollahimohammad., A. Ja'afar., R. 2014. Learning style preferences of nursing students at two universities in Iran and Malaysia Education Eval Health Prof 11 (30), doi: 10.3352/jeehp.2014.11.30

Allan., T.H., Smith., P., O'Driscoll., M., 2011. Experiences of supernumerary status and the hidden curriculum in nursing: a new twist in the theory-practice gap? Journal of Clinical Nursing 20 (5-6), 847-855.

Awuah-Peasah., D., Akuamoah Sarfo., L., Asamoah., F. 2013. The attitudes of student nurses toward clinical work International Journal of Nursing and Midwifery 5(2), 22-27.

Berntsen, K., Bjørk, I.T. 2010. Nursing students' perceptions of the clinical learning environment in nursing homes. Journal Nursing Education 49 (1) 17-22.

Bigdeli. S, Pakpour. V, Aalaa. M, Shekarabi. R, Sanjari. M, Haghani. H, Mehrdad. N 2015. Clinical learning environments (actual and expected): perceptions of Iran University of Medical Sciences nursing students. Medical Journal of the Islamic Republic of Iran (MHIRI) 289(173), 1-8.

Bjørk. IT, Berntsen. K, Brynildsen. G., Hestetun. M. 2014. Nursing students' perceptions of their clinical learning environment in placements outside traditional hospital settings. Journal of Clinical Nursing 23, 2958-2967. 
Boyd-Turner, D,, Bell, E., Russell, A. 2016. The influence student placement experience can have on the employment choices of graduates: a [pediatric nursing context. Nurse Education Today 16(1), 263-268.

Boynton, P.M., 2004. Administering, analysing and reporting your questionnaire. Br. Med. J. $328,1372-1375$.

Brown. T., Williams. B., McKenna. L., Palermo. C., McCall. L., Roller. L., Hewitt. L., Molloy. L., Baird. M. Aldabah. L. 2011. Practice education learning environments: The mismatch between perceived and preferred expectations of undergraduate health science students. Nurse Education Today 31(8), 22-28

Callaghan, A. 2011. Student nurses' perceptions of learning in a perioperative placement. Journal of Advanced Nursing 67(4), 854-64.

Chan, DS. 2002. Development of the clinical learning environment inventory: using the theoretical framework of learning environment studies to assess nursing students' perceptions of the hospital as a learning environment. Journal of Nursing Education 41, 69-75.

Chan, DS. 2003. Validation of the Clinical Learning Environment Inventory. Western Journal of Nursing Research 25(5), 519-32.

Chan, DS. 2004. Nursing students' perceptions of hospital learning environments: an Australian perspective. International Journal of Nursing Education Scholarship 1, 1. 
Chan, DS., Ip, WY. 2007. Perception of hospital learning environment: a survey of Hong Kong nursing students. Nurse Education Today 27(7), 677-84.

Chuan, OL., Barnett, T. 2012. Student, tutor and staff nurse perceptions of the clinical learning environment. Nurse Education in Practice 12(4), 192-97.

Courtney-Pratt, H., FitzGerald, M., Ford, K., Marsden, K., Marlow, A., 2012. Quality clinical placements for undergraduate nursing students: a cross-sectional survey of undergraduates and supervising nurses. Journal of Advanced Nursing 68 (6), 1380-1390

Field, A. 2006. Research Methods II: Reliability Analysis. The University of Sussex, England. Available at: http://www.sussex.ac.uk/Users/andyf/reliability.pdf ( Accessed on 6th July 2015)

Happel. B., Gaskin. CJ. 2013. The attitudes of undergraduate nursing students towards mental health nursing: a systematic review. Journal of Clinical Nursing 22, 148-158.

Happel., B, Platania-Phung., C. 2012. Mental health placements in a general health setting: no substitute for the real thing! Journal of Clinical Nursing 21, 2026-2033.

Harrington. C, Choiniere. J, Goldmann. M, Jacobsen. FF, Lloyd. L, McGregor. M, Stamatopoulos. V., Szebehely. M. 2012. Nursing home staffing standards and staffing levels in six countries. Journal of Nursing Scholarship 44, 88-98. 
Hasson, F. 2012. An investigation into student nurses' perceptions of the role of the healthcare assistant and the influence on students' clinical learning experience. $\mathrm{PhD}$ Unpublished Thesis. Ulster University, Northern Ireland.

Henderson. A, Twentyman. M, Heel. A, Lloyd. B 2006. Students' perception of the psychosocial clinical learning environment: An evaluation of placement models. Nurse Education Today 26, 564-571.

Henning, M., Shulruf, B., Hawken, S., Pinnock, R. 2011. Changing the learning environment: the medical student voice. The Clinical Teacher 8(2), 83-87.

Ip, WY., Chan DSK. 2005. Hong Kong nursing students' perception of the clinical learning environment: a questionnaire study. Journal of Advanced Nursing 42, 665-672.

Kaphagawani. NC., Useh. U. 2013. Analysis of Nursing Students Learning Experiences in Clinical Practice: Literature Review Ethno Med 7(3),181-185.

Killam., L.A., Mossey., S., Montgomery., P., Timmermans., K.E. 2013. First year nursing students' viewpoints about compromised clinical safety. Nurse Education Today 33(5),47580.

Lamont., S, Brunero S., Woods., K. 2015. Satisfaction with clinical placement - the perspective of nursing students from multiple universities. Collegian 22(1), 125-133. 
Leigh., J. 2014. The role of the nurse lecturer situated within a practice-education partnership International Journal of Practice-Based Learning in Health and Social Care 2(1), 122-141.

Leigh J., Hill., P., Bullpit., S., Dean., S., O’Flanagan., S, Fishburn., N. 2014. Opening up placement opportunities for students Nursing Times 110(38), 20-22.

Levett-Jones, T., Lathlean, J., Maguire, J., McMillan, M. 2007. Belongingness: a critique of the concept and implications for nursing education. Nurse Education Today 27(3), 210-218.

McInnes. S, Peters. K, Hardy. J., Halcomb. E. 2015. Primary care clinical placements: The views of Australian registered nurse mentors and pre-registration nursing students (part 2). Nurse Education in Practice 15(6),443-449.

McKenna, L., McCall, L., Wray, N. 2010. Clinical placements and nursing students' career planning: a qualitative exploration. International Journal Nursing. Practice 16(2), 176-182.

Midgley, K. 2006. Pre-registration student nurses perception of the hospital learning environment during clinical placements. Nurse Education Today 26, 338-345.

Moattari M, Ramezani S. 2009 Nursing Students' Perspective toward Clinical Learning Environment. Iranian Journal of Medical Education 9(2), 137-145

Moos, RH. 1974 The Social Climate Scales: An Overview. Palo Alto, California: Consulting Psychologists Press. 
Murphy F, Rosser M, Bevan R, Warner G. Jordan S. 2012. Nursing students' experiences and preferences regarding hospital and community placements. Nurse Education in Practice. $12,170-175$.

Niederhauser V, Schoessler M, Gubrud-Howe PM, Magnussen L. Codier E. 2012. Creating innovative models of clinical nursing education. Journal of Nursing Education 51, 603-608.

O’Reilly-Knapp, M. 1994. Reports by baccalaureate nursing students of social support. The Journal of Nursing Scholarship 26,139-142.

Papathanasiou. IV., Tsaras. K., Sarafis. P. 2014. Views and perceptions of nursing students on their clinical learning environment: teaching and learning. Nurse Education Today 34(1),57-60.

Papp, I., Markkanen, M., Von Bonsdorff, M., 2003. Clinical environment as a learning environment: student nurses' perceptions concerning clinical learning experiences. Nurse Education Today 23, 262-268.

Perli. S., Brugnolli. A. 2009. Italian nursing students' perception of their clinical learning environment as measured with the CLEI tool. Nurse Education Today 29, 886-889.

Polit, D.F., Beck, C.T. 2006. The content validity index: are you sure you know what's being reported? Critique and recommendations. Research Nursing in Health 29, 489-497. 
Poon, W.S. 2014. Nursing students" perception of the clinical learning environment in Macao. Presentation Sigma Theta Tau International the Honor Society of Nursing, $25^{\text {th }}$ International Nursing Research Congress. Available at: http://www.nursinglibrary.org/vhl/handle/10755/335152 (Accessed on 15 February 2016)

Ralph, E., Walker, K., Wimmer, R. 2009. Practicum and clinical experiences: postpracticum students' views. The Journal of Nursing Education 48(8), 434-440.

Rodger., S, Fitzgerald., C, Davila., W, Millar., F, Allison., H. 2011. What makes a quality occupational therapy practice placement? Students' and practice educators' perspectives. Australian Occupational Therapy Journal 58(3), 195-202.

Royal College of Nursing. 2008. Nursing Our Future. An RCN Study into the Challenges Facing Today's Nursing Students in the UK. Royal College of Nursing, London.

Saarikoski., M, Warne., T, Aunio., R. Leino-Kilpi., H. 2006. Group supervision in facilitating learning and teaching in mental health clinical placements: a case example of one student group. Issues in Mental Health Nursing 27, 273-285.

Serena P., Anna B. 2009. Italian nursing students' perception of their clinical learning environment as measured with the CLEI tool. Nurse Education Today 29(8), 886-890.

Siggins Miller Consultants. 2012. Promoting Quality in Clinical Placements: Literature review and national stakeholder consultation, Health Workforce Australia, Adelaide. 
Skaalvik., MW, Normann., K. Henriksen., N. 2011. Clinical learning environment and supervision: experiences of Norwegian nursing students - a questionnaire survey. Journal of Clinical Nursing 20, 2294-2304.

Smedley. A., Morey, P. 2010. Improving learning in the clinical nursing environment: perceptions of senior Australian bachelor of nursing students. Journal of Research in Nursing $5,175-188$.

Tavakol., M. Dennick., R. 2011. Making sense of Cronbach's alpha International Journal of Medical Education 2, 53-55.

The European Directive. 2005. Recognition of Professional Qualifications Article 31 of 2005/36/EC

Thomas., J, Jinks A., Jack, B. 2015. Finessing incivility the professional socialization experiences of student nurses' first clinical placement, a grounded theory. Nurse Education Today 35(12), e4-e9.

Willis Commission. 2012. Quality with Compassion: The Future of Nursing Education. Available at: http://www.williscommission.org.uk/_data/assets/pdf_file/0007/495115/Willis_commission _report_Jan_2013.pdf (Accessed on 18 February 2016). 


\section{INTRODUCTION}

Historically and legally, clinical teaching is one of the major components of nursing worldwide (Siggins Miller Consultants, 2012). As well as clinical skill development, practice in a clinical setting also enables socialization into the professional role (Thomas et al., 2015). The European Directive (2005) for the education of general nurses requires 4,600 hours of theoretical and clinical components, with at least half of this time spent in the clinical setting. In the United Kingdom, $50 \%$ of nurse education is undertaken in the clinical arena, in a range of settings (Murphy et al., 2012) including community and acute. A raft of studies have highlighted that clinical experience influences students attitudes towards that clinical setting (Bjørk et al., 2014, Happel and Gaskin, 2013, Awuah-Peasah et al., 2013 Happel and Platania-Phung, 2012). To the extent that it can sway where they are likely to work once graduated (Boyd-Turner et al., 2016, McKenna et al., 2010). Therefore, it is vital that practice learning experience is of high quality and valued by pre-registration nurses in order to enhance student's learning outcomes.

Yet questions regarding the quality of the placement have arisen (Willis Commission, 2012, Royal College of Nursing, 2008) with evidence suggesting that students do not believe that all clinical learning environments are conducive to learning (Callaghan, 2011, Perli and Brugnolli, 2009). Given the acute shortage of clinical placement positions, it is important that such environments are "suited to students' perceptions and expectations" (Brown et al., 2011, p e22). However the majority of research from the student perspective of placement has focused on acute sector placements (Bjørk et al., 2014). The purpose of this study is to assess students' views and perceptions of their most recent clinical learning environment, including hospital, community, surgical and other (nursing home). 


\section{BACKGROUND/ LITERATURE}

Clinical nurse education is located within a range of settings, each presenting its own complex social environment. In each setting, the student nurse has a dual role of learner and active involvement, contributing to patient care (Allan et al., 2011). However, clinical learning occurs in an environment designed for clinical services rather than education (Henning et al., 2011). Therefore, a lack of control of the environment may influence the quality of the student learning. Nevertheless, research has identified that sociocultural characteristics of a learning environment can influence students' experiences (Moos, 1974). In reviewing clinical education experiences of nurses, Chan (2003) outlined the six psychosocial aspects students identify as important in the clinical learning environment (see table 1).

\section{Insert table 1 here}

The six psycho-social aspects form the basis of the Clinical Learning Environment Inventory (CLEI) (Chan, 2003), which is one of the most commonly used instruments used to measure students' perceptions (Bjørk et al., 2014). The tool consists of two scales (Actual and Expected). The actual scale measures the actual learning environment, whilst the expected assesses what the students would ideally like in the clinical environment. The application of the actual tool has mostly been used to access students' views of hospital placements (Bigdeli et al., 2015, Poon 2014, Papathanasiou et al., 2014, Perli and Brugnoilli, 2009, Midgley 2006, Henderson et al., 2006). However, a growing body of research has started to explore other clinical settings such as nursing homes (Berntsen and Bjørk, 2010), mental health facilities (Saarikoski et al., 2006) and primary care practices (McInnes et al., 2015). The tool has been found to be homogeneous and its validity established in several countries worldwide including Greece (Papathanasiou et al., 2014), Italy (Serena and Anna 2009), and Australia 
(Chan, 2003). In addition, Chan (2003) and colleagues (2007) reported good psychometric properties of the tool with established internal reliability (Chan, 2003, Perli and Brugnolli, 2009, Bjork et al., 2014) and discriminant validity (Chan, 2003, Chan and Ip, 2007). For example, Chan (2007) reported the Cronbach alpha coefficients ranging from 0.73-0.84 and 0.66-0.80 respectively for the actual and expected scales. With regards to face validity, items of the CLEI tool were derived from the literature, modified classroom environment tool and a panel of experts. This is an accepted approach to computing the face validity index (Polit and Beck, 2006).

Previous research has consistently reported that students perceive personalisation to be of primary importance (Siggins Miller Consultants, 2012). Such findings are common themes across health setting, discipline and country (Bigdeli et al,. 2015; Papathanasiou et al., 2014, Rodger et al., 2011, Brown et al., 2011, Smedley and Morey, 2010, Ralph et al., 2009). Nursing research supports this, for example, a number of authors report that good communication and collaboration between student's clinical tutors and/or practitioners (Courtney-Pratt et al., 2012, Brown et al., 2011, Smedley and Morey, 2010), involvement in practice (Chuan and Barnett, 2012), and feeling part of the team (Midgley, 2006, Papp et al., 2003), can affect the acquisition of skills, knowledge and professionalism. However, research suggests that access to qualified supervision and support is unstandardized across clinical environments, such as nursing homes (Harrington et al., 2012).

Results from previous CLEI studies indicate that nursing students are involved in the accomplishment of tasks, albeit at varying levels (Smedley and Morey, 2009, Perli and Brugnolli, 2009, Henderson et al., 2006). However, reports that students are doing routine and non-nursing duties (Hasson, 2012) suggest that some placement areas may limit access to 
challenging learning opportunities for students, stifling occasions to learn critical and clinical judgement skills (Kaphagawani and Useh, 2013).

Concepts such as innovation have not featured strongly in some CELI studies (Papathanasiou et al., 2014, Smedley and Morey, 2009, Chan and Ip, 2007, Midgley, 2006, Henderson et al., 2006), and a number of studies have reported individualisation to have low scores (Berntsen and Bjørk, 2010, Perli and Brugnolli, 2009, Ip and Chan, 2005). However, Bjørk et al. (2014) reported that mental health care students scored this concept as high, attributing this to characteristics of the placement setting.

Students' level of satisfaction score with clinical placement reportedly varies. In a UK study, Murphy et al. (2012) compared students' level of satisfaction across hospital and community placement settings and reported that district nursing was the best liked placement. Whilst in a Norwegian study, Skaalvik et al. (2011) reported that students assessed nursing home placements negatively. However, satisfaction score can be influenced by a number of factors, such as level of engagement, feeling part of a team, and being involved in well-organised activities (Lamont et al., 2015, Levett-Jones et al., 2007). Two Iranian studies concluded that satisfaction was not considered in clinical education environments (Bigdeli et al., 2015; Moattari and Ramezani, 2009), despite Chan and Ip (2007) viewing it as an education outcome requiring the attention of nursing authorities and policy makers.

\section{METHODS}

This was a descriptive, cross-sectional online survey. With permission of the author (Chan, 2002), the actual CLEI questionnaire was used. It consists of 40 items grouped into six construct scales with each scale consisting of seven Likert (four-point) scale type questions 
(1-4, 1 being strongly negative and 4 being strongly positive). Two of the questions were excluded as they were felt to be non-applicable to the areas of clinical learning. The validity of the modified sub scale was confirmed prior to full analysis. A pilot study was conducted with 51 third year pre-registration nursing students (adult branch), not included in the main study, and reviewed by a panel of education experts to ensure the appropriateness of wording and understanding. This process contributed to the reliability and validity of the questionnaire and helped to ensure clarity and ease of administration (Boynton, 2004).

In addition to the CLEI tool, a demographics section was added to the questionnaire, to enable baseline characteristics of respondents to be summarised. Cronbach alpha coefficients of CLEI scale have ranged from 0.73 to 0.84 (Chan, 2003). These Cronbach alpha coefficients confirmed reliability however Chan and Ip (2007) reported less reliable Cronbachs alpha of $0.5-0.8$, following modification of the instrument. The Cronbach alpha coefficients for this study for each scale ranged from 0.61-0.90, which confirm a very satisfactory level of scale reliability ( Tavakol and Dennick, 2011).

\section{Setting and Sample}

All adult and mental health nursing students enrolled on the BSc (Hons) programme ( $\mathrm{n}=633$ ) from one higher educational institution in the United Kingdom were surveyed during March 2014. All nursing students had experience of clinical placement. The range of placement areas include, Community, Hospital, Learning Disability and Mental Health, Community Public Health, Critical care, Perioperative care, Public Health, Continuing Care and Chronic Illness, Multi-disciplinary Team Assessment and Rehabilitation, and Management.

\section{Data collection}


Full ethical approval was obtained prior to data collection, from the host educational institution. An invitation email, with a link to a participant information sheet and the questionnaire, was administered to all first, second and final year nursing students. To encourage survey completion, reminder emails were issued at weeks one and two, and oral presentations about the research given to each year group (by author EMcC not associated with any teaching responsibilities). Return of the questionnaire implied consent and potential respondents were guaranteed anonymity.

\section{Data analysis}

Results were collected using QUALTRICS and analysed using Statistical Package for Social Sciences (SPSS) Statistics Software (Version 21). Data were checked for missing responses and central tendencies calculated. Normality and distribution was determined through the appropriate statistical test. Multiple regression analysis was used to identify independent variables where further statistical examinations were required, thereby reducing the potential of multiplicity. Statistical significant results mean differences were examined, to describe the survey data for each cohort and placement area.

\section{DATA/RESULTS}

From a potential population of 633 nursing students, 152 completed the CLEI questionnaire, giving a response rate of $24 \%$. Data cleaning techniques identified five participants had not completed more than $10 \%$ of the questionnaire, leaving 147 useable data sets for analysis. Based on the Raosoft sample calculator, with a population of $633,95 \%$ confidence level; and a response distribution of $50 \%$ a response rate of $n=147$ produced a margin of error of $7.1 \%$. Demographic information $(n=147)$, revealed that the highest proportion of respondents were 
female, aged 18-24 and third year students in the adult branch, who completed their practice learning experience in the hospital setting. (See table 2).

\section{Insert table 2 here}

\section{Measures of distribution}

Measures of skewness and kurtosis are within the acceptable range, justifying the use of parametric statistics tests throughout (see table 3). Internal consistency of the items was measured by using Cronbach's alpha coefficients. Cronbach Alpha scores show that four of the six constructs were above the acceptable threshold of 0.7 ; with two constructs achieving scores in the banding 0.6-0.7. Item deletion failed to correct for low Alpha scores. Psychological constructs values below 0.7 have been attributed to the diversity of the constructs being measured (Field, 2006).

\section{Insert table 3 here}

Students were moderately satisfied with their clinical learning experience. With a maximum score of four was possible, the mean score ranged from 2.48-3.20 indicating a positive but not strongly positive view (table 3). The subscale 'Satisfaction' gained the highest mean score 3.20, indicating a more positive perception. The innovation sub scale gained the lowest mean score 2.48 , highlighting a need for improvement in this area.

The majority of the CLEI frequency scores were positively scored (see table 4). The highest scored item was 'Students pay attention to what others are saying'. Within the CLEI 'others' are not specified, however, this could be mentors, preceptors or academic members of staff. 
Other high score items include 'Students put effort into what they do on their practice learning experience', and 'This practice learning experience is a waste of time'.

Not all students felt positively about the experience. Table 4 shows that almost half $(46.3 \%)$ of participants felt 'New ideas were seldom tried out in this area', and $12.9 \%$ disagreed that 'After the shift the student has a sense of satisfaction'. Scores regarding the mentor's role were also negatively scored for example, 'The Mentor is unfriendly and inconsiderate towards students', 'Mentor is not interested in student problems' and 'Mentors dominates briefing sessions/ review of progress'.

\section{Insert table 4 here}

The CLEI works on six construct factors, factor items were aggregated to generate factor scores. Examination of a correlation matrix show high positive correlations of all six factors, with 12 of 15 relationship scored between $.05-071$, at a statistically significant level $(\mathrm{p}=0.01$, 1-tailed). One-way ANOVA was undertaken of each of the six scales of the tool across each clinical placement setting in order to identify differences in student experiences. Differences across subgroups (i.e. student gender, and branch), were tested with T-tests and differences in age group or student year, and clinical placement were tested using one-way ANOVA (see table 5).

\section{Insert table 5 here}

Statistically significant difference noted on 'Personalisation' $(F(2,146)=3.667, p=0.028)$ across placement settings. Post hoc Scheffe analysis indicated the differences were between 
hospital and community placements $(\mathrm{p}=0.033)$ where community placement students had significantly higher scores (see table 4). No statistical differences were noted according to gender of students due to small number of male students $(n=11)$ therefore limiting comparisons.

There was a statistically significant difference in the satisfaction sub scale for the student year groups $(\mathrm{F}(2,144)=4.102, \mathrm{p}=0.019)$. Post hoc comparisons Scheffe test indicated the mean score for Year $1(\mathrm{M}=3.40, \mathrm{SD}=0.42)$ did differ significantly from Year $2(\mathrm{M}=3.06$, $\mathrm{SD}=0.71)$ and Year $3(\mathrm{M}=3.18, \mathrm{SD}=0.48)$, highlighted with a $\mathrm{p}$ value $\mathrm{p}=0.22$. Assumption of homogeneity of variance was violated for the mean 'Satisfaction' sub scale score, so Robust Tests of Equality of means was examined. Brown -Forsythe and Welch show (Sig) P value of 0.01 and 0.03 respectively indicating that satisfaction rating is affected by year. Year one to year three scores gradually decrease across years on sub scales including personalisation, involvement and task orientation. When comparing across different years, year one recorded a higher score. These indicate their experience of these constructs of their clinical learning experience are more positive than second year and second year students have a more positive experience than third year students.

Statistically significant differences were noted across nursing courses on one construct 'Individualisation' where Mental Health nurses scored the construct higher than Adult Nurses $(\mathrm{T}(144)=-2.144, \mathrm{p}=0.034) . \quad$ Examinations of differences of perceptions between age groups were conducted using One-way ANOVA with students categorised into four groups; 18-24, 25-34, 35-44, 45-54. Means and standard deviation are detailed (Table 5). A statistical difference was noted and showed a small difference between age groups in the 'Involvement' sub scale with a p-value of 0.01 , however, the other five sub scale scores were 
not statistically significant. Post-hoc comparisons using Scheffe test indicated a significant difference for the mean score for age groups 18-24 and 35-44.

The items of the CLEI were individually analysed according to clinical placement (see table 6). Of the 42 items, eight were identified as having statistically significant differences and post hoc tests indicate where these differences existed. Table 6 shows the level of statistical significance and examination of the pattern of responses show that Community scored the items higher in all 8 items and generally surgical scored it lowest. Post hoc analysis report significant differences between community and hospital scores on items 2, 3, 4, 5, 6, 7; and community and surgical on items 1 and 7.

\section{Insert table 6 here}

\section{DICSUSSION}

The actual experiences of pre-registration nursing students of their most recent practice learning experience were examined and compared to their perceptions across student year groups, demographics and placement type. Findings indicate that pre-registration students had different perceptions of their clinical learning experience in the clinical setting. In general, students were satisfied with their clinical learning experience, with a positive but not strongly positive view.

Based on Chan's (2003) six psycho-social aspects, satisfaction was rated the highest, followed by personalization and reflective of previous research (Midgley, 2006, Chan, 2002). It seems that students are looking for support and acknowledgement of their progress, and rate this as a top priority in their clinical learning experience (Bernsten and Bjørk, 2010). 
The importance of human relationships in clinical learning is a concurrent theme in the literature (Papathanasiou et al., 2014, Henderson et al., 2006, Chan, 2002), which is unsurprising given that supportive relationships can trigger internalization of the professional role (Killam et al., 2013). This is why establishing effective working relations is the first outcome for a stage two mentor (NMC, 2008).

However this study's results are slightly different in that "satisfaction" was the highest score rather than "personalisation" as in previous studies (Papathanasiou et al., 2014, Berntsen and Bjørk , 2010, Perli and Brugnolli, 2009, Smedley and Morey, 2009, Chan and Ip, 2007, Ip and Chan, 2005). This suggests that students generally experienced a less than positive clinical placement experience, especially related innovation and individualization issues. These issues require careful consideration for future placement of students.

The innovation sub scale gained the lowest mean score, reflecting previous research (Bernsten and Bjørk, 2010, Chan and Ip, 2007, Midgley, 2006). Such findings may be attributed to the perceived routine nature of care and indicate mentors may not have fulfilled this part of their role. This is despite research recommending that mentors spend more time ensuring a creative and innovative experience which should be provided through academicpractice agreements (Niederhauser et al., 2012, Chan, 2002). However the realities of staff shortages, economic cuts, and increasing clinical demands, may hamper the ability to provide such experiences and new ways of working.

Results from the "Satisfaction" sub scale in this study were found to be positively associated with other sub scales in the CLEI. Chan (2002) recommends the use of the sub scale 'satisfaction' as an outcome measure for the overall perception of learning environment. This 
has been examined in previous studies and used as an overall indicator of the pre-registration nurse's experience (Papathanasious et al., 201,; Brown et al., 2011, Berntsen and Bjørk, 2010, Chan and Ip, 2007). Findings in this study suggest that all five sub scales were significant predictors and account for $55 \%$ of the total variance. This appears to relate strongly to overall satisfaction of clinical learning experience. Papathanasiou et al. (2014) adds that effective participation of students leads to positive experience in the working environment. Involvement, however, requires the student to be able to take part and work as part of the team, enabling students to carry out tasks and develop skills and confidence with practice. However, many students perceive their learning experience as anxiety provoking and it has been reported by Chan (2002) that this feeling often leaves students when they are busy with placement activities.

Reflective of Bjørk et al. (2014), work differences between placement groups were not highly significant. There are comparisons regarding the best type of clinical learning experience (Murphy et al., 2012), however, no overall significant difference were observed in this study. Differences between age groups (18-24 and 35-44), in the involvement sub scale were reported, which may be attributed to 18-24 age group still developing confidence and integration skills within a clinical setting. Whereas, the 35-44 age group involvement score may be underpinned by entering nurse education with prior work/ life experience (Hasson 2012), having greater motivation, and an overall maturity enabling them to deal with varied situations (Bjørk et al., 2014). Nursing educational literature suggests that consideration of the students individual learning styles should be considered in order to maximise the learning experience (Midgley, 2006). Smedley and Morey (2009) add that in nurse education, teaching styles rely on an adult learning approach, which may not be appropriate for the young adult learner (Abdollahimohammad and Ja'afar 2014, Smedley and Morey, 2009). 
These findings highlight the need to examine further the effect of student's age on the perceptions of their clinical learning experience.

CLEI scores indicate that satisfaction scores were affected by year. This is contrary to Ip and Chan's (2005) study which reported that year three and four had a more positive experience, and with O’Reilly Knapp's (1994) findings who reported there was no difference between age groups in overall satisfaction scores. It has been recognised that year one for nursing students is a transitional period and may be seen as a culture shock (Ip and Chan, 2005), therefore, additional effort may be made to provide these students with more preparation and greater support and encouragement. Years two and three may have developed a greater insight into the learning environment and what is expected from them and their mentors and may feel that this is not achieved.

The CELI, based on Moos' (1974) theoretical framework, emphasises the importance of relationships, personal, and system (maintenance and change) dimensions. Findings of this study suggest that each domain has a relative value of importance for the student nurse. The need to prepare students across each of these domains using innovative approaches to enhance perpetration for the reality of their role has been advocated (Neiderhauser et al., 2012). Central to this, is the development of academic-practice collaborations to reduce the theory practice gap, between learning and clinical realities. This may be achieved by adopting innovative placement allocations (Leigh et al., 2014) or positioning the academic lecturer in clinical practice (Leigh, 2014), to build upon personalisation and individualisation issues.

\section{Limitations}


This study has a number of strengths, for example, being based on a previous validated instrument, the inclusion of a diversity of student years, age groups and perspectives from multiple clinical sites. Several limitations must also be recognised. First, this study was undertaken within one higher educational institution, questioning generalization of the findings. Second, a low response rate was achieved from the overall study population, suggesting possible risk of bias. Nevertheless according to the literature, the overall response rate was high. Third, the cross-sectional design does not provide definite information about the cause-and-effect relationship. Finally, although the curricular for pre-registration nursing education in the United Kingdom is similar to other countries, differences regarding clinical placements and mentorships styles must also be considered.

\section{CONCLUSIONS}

The results show that pre-registration nursing students are positive about their perceptions of the clinical learning environment, however generally there is room for improvement. Students who scored a high level on the sub scale satisfaction also scored a high level on the other five sub scales namely, personalisation, involvement, task orientation, innovation and individualisation showing a strong association between these. Findings confirm the importance of personalisation and sense of belonging and acceptance for nursing students to be a key factor in the clinical learning environment. Further research exploring differing clinical learning environments is recommended. In addition it may also be useful to examine in detail why age and year affect perceptions of the clinical learning environment. Clinical placement experience is vital in the delivery of health education. Therefore, it is important to assess the students' experience to ensure the clinical learning experience meets their needs at every stage in their training, to enable the preparation and development of future nurses. 


\section{REFERENCES}

Abdollahimohammad., A. Ja'afar., R. 2014. Learning style preferences of nursing students at two universities in Iran and Malaysia Education Eval Health Prof 11 (30), doi: 10.3352/jeehp.2014.11.30

Allan., T.H., Smith., P., O'Driscoll., M., 2011. Experiences of supernumerary status and the hidden curriculum in nursing: a new twist in the theory-practice gap? Journal of Clinical Nursing 20 (5-6), 847-855.

Awuah-Peasah., D., Akuamoah Sarfo., L., Asamoah., F. 2013. The attitudes of student nurses toward clinical work International Journal of Nursing and Midwifery 5(2), 22-27.

Berntsen, K., Bjørk, I.T. 2010. Nursing students' perceptions of the clinical learning environment in nursing homes. Journal Nursing Education 49 (1) 17-22.

Bigdeli. S, Pakpour. V, Aalaa. M, Shekarabi. R, Sanjari. M, Haghani. H, Mehrdad. N 2015. Clinical learning environments (actual and expected): perceptions of Iran University of Medical Sciences nursing students. Medical Journal of the Islamic Republic of Iran (MHIRI) 289(173), 1-8.

Bjørk. IT, Berntsen. K, Brynildsen. G., Hestetun. M. 2014. Nursing students' perceptions of their clinical learning environment in placements outside traditional hospital settings. Journal of Clinical Nursing 23, 2958-2967. 
Boyd-Turner, D,, Bell, E., Russell, A. 2016. The influence student placement experience can have on the employment choices of graduates: a [pediatric nursing context. Nurse Education Today 16(1), 263-268.

Boynton, P.M., 2004. Administering, analysing and reporting your questionnaire. Br. Med. J. $328,1372-1375$.

Brown. T., Williams. B., McKenna. L., Palermo. C., McCall. L., Roller. L., Hewitt. L., Molloy. L., Baird. M. Aldabah. L. 2011. Practice education learning environments: The mismatch between perceived and preferred expectations of undergraduate health science students. Nurse Education Today 31(8), 22-28

Callaghan, A. 2011. Student nurses' perceptions of learning in a perioperative placement. Journal of Advanced Nursing 67(4), 854-64.

Chan, DS. 2002. Development of the clinical learning environment inventory: using the theoretical framework of learning environment studies to assess nursing students' perceptions of the hospital as a learning environment. Journal of Nursing Education 41, 69-75.

Chan, DS. 2003. Validation of the Clinical Learning Environment Inventory. Western Journal of Nursing Research 25(5), 519-32.

Chan, DS. 2004. Nursing students' perceptions of hospital learning environments: an Australian perspective. International Journal of Nursing Education Scholarship 1, 1. 
Chan, DS., Ip, WY. 2007. Perception of hospital learning environment: a survey of Hong Kong nursing students. Nurse Education Today 27(7), 677-84.

Chuan, OL., Barnett, T. 2012. Student, tutor and staff nurse perceptions of the clinical learning environment. Nurse Education in Practice 12(4), 192-97.

Courtney-Pratt, H., FitzGerald, M., Ford, K., Marsden, K., Marlow, A., 2012. Quality clinical placements for undergraduate nursing students: a cross-sectional survey of undergraduates and supervising nurses. Journal of Advanced Nursing 68 (6), 1380-1390

Field, A. 2006. Research Methods II: Reliability Analysis. The University of Sussex, England. Available at: http://www.sussex.ac.uk/Users/andyf/reliability.pdf ( Accessed on 6th July 2015)

Happel. B., Gaskin. CJ. 2013. The attitudes of undergraduate nursing students towards mental health nursing: a systematic review. Journal of Clinical Nursing 22, 148-158.

Happel., B, Platania-Phung., C. 2012. Mental health placements in a general health setting: no substitute for the real thing! Journal of Clinical Nursing 21, 2026-2033.

Harrington. C, Choiniere. J, Goldmann. M, Jacobsen. FF, Lloyd. L, McGregor. M, Stamatopoulos. V., Szebehely. M. 2012. Nursing home staffing standards and staffing levels in six countries. Journal of Nursing Scholarship 44, 88-98. 
Hasson, F. 2012. An investigation into student nurses' perceptions of the role of the healthcare assistant and the influence on students' clinical learning experience. PhD Unpublished Thesis. Ulster University, Northern Ireland.

Henderson. A, Twentyman. M, Heel. A, Lloyd. B 2006. Students' perception of the psychosocial clinical learning environment: An evaluation of placement models. Nurse Education Today 26, 564-571.

Henning, M., Shulruf, B., Hawken, S., Pinnock, R. 2011. Changing the learning environment: the medical student voice. The Clinical Teacher 8(2), 83-87.

Ip, WY., Chan DSK. 2005. Hong Kong nursing students' perception of the clinical learning environment: a questionnaire study. Journal of Advanced Nursing 42, 665-672.

Kaphagawani. NC., Useh. U. 2013. Analysis of Nursing Students Learning Experiences in Clinical Practice: Literature Review Ethno Med 7(3),181-185.

Killam., L.A., Mossey., S., Montgomery., P., Timmermans., K.E. 2013. First year nursing students' viewpoints about compromised clinical safety. Nurse Education Today 33(5),47580.

Lamont., S, Brunero S., Woods., K. 2015. Satisfaction with clinical placement - the perspective of nursing students from multiple universities. Collegian 22(1), 125-133. 
Leigh., J. 2014. The role of the nurse lecturer situated within a practice-education partnership International Journal of Practice-Based Learning in Health and Social Care 2(1), 122-141.

Leigh J., Hill., P., Bullpit., S., Dean., S., O’Flanagan., S, Fishburn., N. 2014. Opening up placement opportunities for students Nursing Times 110(38), 20-22.

Levett-Jones, T., Lathlean, J., Maguire, J., McMillan, M. 2007. Belongingness: a critique of the concept and implications for nursing education. Nurse Education Today 27(3), 210-218.

McInnes. S, Peters. K, Hardy. J., Halcomb. E. 2015. Primary care clinical placements: The views of Australian registered nurse mentors and pre-registration nursing students (part 2). Nurse Education in Practice 15(6),443-449.

McKenna, L., McCall, L., Wray, N. 2010. Clinical placements and nursing students' career planning: a qualitative exploration. International Journal Nursing. Practice 16(2), 176-182.

Midgley, K. 2006. Pre-registration student nurses perception of the hospital learning environment during clinical placements. Nurse Education Today 26, 338-345.

Moattari M, Ramezani S. 2009 Nursing Students' Perspective toward Clinical Learning Environment. Iranian Journal of Medical Education 9(2), 137-145

Moos, RH. 1974 The Social Climate Scales: An Overview. Palo Alto, California: Consulting Psychologists Press. 
Murphy F, Rosser M, Bevan R, Warner G. Jordan S. 2012. Nursing students' experiences and preferences regarding hospital and community placements. Nurse Education in Practice. $12,170-175$.

Niederhauser V, Schoessler M, Gubrud-Howe PM, Magnussen L. Codier E. 2012. Creating innovative models of clinical nursing education. Journal of Nursing Education 51, 603-608.

O’Reilly-Knapp, M. 1994. Reports by baccalaureate nursing students of social support. The Journal of Nursing Scholarship 26,139-142.

Papathanasiou. IV., Tsaras. K., Sarafis. P. 2014. Views and perceptions of nursing students on their clinical learning environment: teaching and learning. Nurse Education Today 34(1),57-60.

Papp, I., Markkanen, M., Von Bonsdorff, M., 2003. Clinical environment as a learning environment: student nurses' perceptions concerning clinical learning experiences. Nurse Education Today 23, 262-268.

Perli. S., Brugnolli. A. 2009. Italian nursing students' perception of their clinical learning environment as measured with the CLEI tool. Nurse Education Today 29, 886-889.

Polit, D.F., Beck, C.T. 2006. The content validity index: are you sure you know what's being reported? Critique and recommendations. Research Nursing in Health 29, 489-497. 
Poon, W.S. 2014. Nursing students" perception of the clinical learning environment in Macao. Presentation Sigma Theta Tau International the Honor Society of Nursing, $25^{\text {th }}$ International Nursing Research Congress. Available at: http://www.nursinglibrary.org/vhl/handle/10755/335152 (Accessed on 15 February 2016)

Ralph, E., Walker, K., Wimmer, R. 2009. Practicum and clinical experiences: postpracticum students' views. The Journal of Nursing Education 48(8), 434-440.

Rodger., S, Fitzgerald., C, Davila., W, Millar., F, Allison., H. 2011. What makes a quality occupational therapy practice placement? Students' and practice educators' perspectives. Australian Occupational Therapy Journal 58(3), 195-202.

Royal College of Nursing. 2008. Nursing Our Future. An RCN Study into the Challenges Facing Today's Nursing Students in the UK. Royal College of Nursing, London.

Saarikoski., M, Warne., T, Aunio., R. Leino-Kilpi., H. 2006. Group supervision in facilitating learning and teaching in mental health clinical placements: a case example of one student group. Issues in Mental Health Nursing 27, 273-285.

Serena P., Anna B. 2009. Italian nursing students' perception of their clinical learning environment as measured with the CLEI tool. Nurse Education Today 29(8), 886-890.

Siggins Miller Consultants. 2012. Promoting Quality in Clinical Placements: Literature review and national stakeholder consultation, Health Workforce Australia, Adelaide. 
Skaalvik., MW, Normann., K. Henriksen., N. 2011. Clinical learning environment and supervision: experiences of Norwegian nursing students - a questionnaire survey. Journal of Clinical Nursing 20, 2294-2304.

Smedley. A., Morey, P. 2010. Improving learning in the clinical nursing environment: perceptions of senior Australian bachelor of nursing students. Journal of Research in Nursing $5,175-188$.

Tavakol., M. Dennick., R. 2011. Making sense of Cronbach's alpha International Journal of Medical Education 2, 53-55.

The European Directive. 2005. Recognition of Professional Qualifications Article 31 of 2005/36/EC

Thomas., J, Jinks A., Jack, B. 2015. Finessing incivility the professional socialization experiences of student nurses' first clinical placement, a grounded theory. Nurse Education Today 35(12), e4-e9.

Willis Commission. 2012. Quality with Compassion: The Future of Nursing Education. Available at: http://www.williscommission.org.uk/_data/assets/pdf_file/0007/495115/Willis_commission _report_Jan_2013.pdf (Accessed on 18 February 2016). 
Table 1: CLEI Scale Descriptors

\begin{tabular}{|l|l|}
\hline Psycho-social & Scale Descriptors \\
\hline Personalisation & $\begin{array}{l}\text { Emphasis on opportunities for the individual student to interact with clinical } \\
\text { teacher/clinician and on concern for student's personal welfare }\end{array}$ \\
\hline Involvement & Extent to which students participate actively and attentively in hospital ward \\
activities
\end{tabular}

(Source: Chan 2003) 
Table 2: Respondent Distribution across demographics

\begin{tabular}{|l|l|l|}
\hline Categories & Demographic Characteristics & $\%$ of respondents (n) \\
\hline Gender & Female & $92.5 \%(135)$ \\
& Male & $7.5 \%(11)$ \\
\hline Age group & $18-24$ & $49.7 \%(73)$ \\
& $25-34$ & $27.2 \%(40)$ \\
& $35-44$ & $19.7 \%(29)$ \\
& $45-55$ & $3.4 \%(5)$ \\
\hline Branch & Adult & $74.0 \%(108)$ \\
& Mental Health & $26.0 \%(38)$ \\
\hline Year & First Year & $24.4 \%(36)$ \\
& Second Year & $25.9 \%(38)$ \\
& Third Year & $49.7 \%(73)$ \\
\hline Placement & Hospital & $54.1 \%(79)$ \\
& Community & $37.7 \%(55)$ \\
& Surgical & $5.5 \%(8)$ \\
\hline
\end{tabular}


Table 3 Key statistical measures of the 6 constructs of the CLEI including descriptive statistics, skewness, kurtosis and Cronbach's Alpha Scores

\begin{tabular}{|c|c|c|c|c|c|}
\hline Construct & Definition & Mean & Skewness & Kurtosis & $\begin{array}{l}\text { Cronback's } \\
\text { Alpha }\end{array}$ \\
\hline Individualisation & $\begin{array}{l}\text { Extent to which students are } \\
\text { allowed to make decisions and } \\
\text { are treated differently } \\
\text { according to ability or interest }\end{array}$ & $\begin{array}{l}2.53 \\
(0.41)\end{array}$ & -0.34 & -0.15 & .63 \\
\hline Innovation & $\begin{array}{l}\text { Extent to which clinical } \\
\text { teacher/clinician plans new, } \\
\text { interesting, and productive } \\
\text { ward experiences, teaching } \\
\text { techniques, learning activities, } \\
\text { and patient allocations. }\end{array}$ & $\begin{array}{l}2.48 \\
(0.53)\end{array}$ & 0.26 & -0.25 & .77 \\
\hline Involvement & $\begin{array}{l}\text { Extent to which students } \\
\text { participate actively and } \\
\text { attentively in hospital ward } \\
\text { activities }\end{array}$ & $\begin{array}{l}2.95 \\
(0.40)\end{array}$ & 0.15 & -0.26 & .61 \\
\hline Personalisation & $\begin{array}{l}\text { Emphasis on opportunities for } \\
\text { individual student to interact } \\
\text { with clinical teacher/clinician } \\
\text { and on concern for student's } \\
\text { personal welfare. }\end{array}$ & $\begin{array}{l}3.03 \\
(0.60)\end{array}$ & -.73 & 0.91 & .90 \\
\hline Task Orientation & $\begin{array}{l}\text { Extent to which ward } \\
\text { activities are clear and well } \\
\text { organised. }\end{array}$ & $\begin{array}{l}2.91 \\
(0.46)\end{array}$ & -0.22 & -.18 & .75 \\
\hline
\end{tabular}




\begin{tabular}{|l|l|l|l|l|l|}
\hline Satisfaction & $\begin{array}{l}\text { Extent of enjoyment of clinical } \\
\text { placement. }\end{array}$ & 3.20 & -.97 & 1.76 & .89 \\
& $(0.55)$ & & & \\
\hline
\end{tabular}


Table 4: Frequency scores of Clinical Learning Environment Inventory items

\begin{tabular}{|c|c|c|c|c|}
\hline ITEMS & \begin{tabular}{l|} 
Strongly \\
Disagree
\end{tabular} & Disagree & Agree & $\begin{array}{l}\text { Strongly } \\
\text { Agree }\end{array}$ \\
\hline The mentor considers students' feelings & 3.4 & 11.0 & 59.6 & 26.0 \\
\hline The mentor talks rather than listens to the students & 11.6 & 33.3 & 45.6 & 9.5 \\
\hline $\begin{array}{l}\text { Students look forward to coming to their practice } \\
\text { learning experience }\end{array}$ & 2.0 & 12.9 & 55.8 & 29.3 \\
\hline $\begin{array}{l}\text { Students know exactly what has to be done in the } \\
\text { practice learning experience }\end{array}$ & 5.4 & 36.7 & 49.7 & 8.2 \\
\hline New ideas are seldom tried out in this area & 4.8 & 49.0 & 45.6 & 0.7 \\
\hline $\begin{array}{l}\text { All staff in this area are expected to do the same work } \\
\text { in the same way }\end{array}$ & 11.0 & 39.0 & 43.2 & 6.8 \\
\hline The mentor talks individually with the students & 1.4 & 6.8 & 61.9 & 29.9 \\
\hline $\begin{array}{l}\text { Students put effort into what they do on their practice } \\
\text { learning experience }\end{array}$ & 0 & 0 & 32.7 & 67.3 \\
\hline Students are dissatisfied with what is done in the area & 2.7 & 20.5 & 61.0 & 15.8 \\
\hline $\begin{array}{l}\text { Getting a certain amount of work done in important in } \\
\text { this area }\end{array}$ & 0.7 & 6.1 & 55.8 & 37.4 \\
\hline $\begin{array}{l}\text { Students are generally allowed to work at their own } \\
\text { pace }\end{array}$ & 8.2 & 34.0 & 51.7 & 6.1 \\
\hline The mentor goes out of his/her way to help students & 5.4 & 23.8 & 47.6 & 23.1 \\
\hline $\begin{array}{l}\text { Students clock watch in this area (cant wait until the } \\
\text { end of shift) }\end{array}$ & 6.2 & 31.5 & 43.8 & 18.5 \\
\hline After the shift the student has a sense of satisfaction & 2.0 & 10.9 & 61.9 & 25.2 \\
\hline $\begin{array}{l}\text { The mentor often gets side tracked instead of sticking to } \\
\text { the point }\end{array}$ & 8.2 & 32.0 & 54.4 & 5.4 \\
\hline The mentor thinks up innovative activities for students & 10.3 & 38.4 & 41.8 & 9.6 \\
\hline
\end{tabular}




\begin{tabular}{|c|c|c|c|c|}
\hline Students have a say in how their shift is spent & 10.2 & 46.3 & 37.4 & 6.1 \\
\hline $\begin{array}{l}\text { The mentor helps the student who is having difficulty } \\
\text { with the work }\end{array}$ & 6.3 & 16.7 & 59.7 & 17.4 \\
\hline $\begin{array}{l}\text { Students in this area pay attention to what others are } \\
\text { saying }\end{array}$ & 0 & 0 & 64.4 & 35.6 \\
\hline This practice learning experience is a waste of time & 2.8 & 4.8 & 28.3 & 64.1 \\
\hline This is a disorganised learning experience & 6.3 & 15.3 & 50.0 & 28.5 \\
\hline $\begin{array}{l}\text { Teaching approaches in this environment are } \\
\text { characterised by innovation and variety }\end{array}$ & 4.1 & 36.3 & 54.1 & 5.5 \\
\hline $\begin{array}{l}\text { Students are allowed to negotiate their work load in this } \\
\text { area }\end{array}$ & 6.2 & 40.0 & 49.7 & 4.1 \\
\hline The mentor seldom goes around to talk to students & 4.1 & 20.0 & 57.2 & 18.6 \\
\hline $\begin{array}{l}\text { Students have little opportunity to be involved with the } \\
\text { handover of patients to other staff }\end{array}$ & 7.5 & 21.9 & 44.5 & 26.0 \\
\hline This practice learning experience was boring & 4.1 & 8.2 & 40.1 & 47.6 \\
\hline Assigned tasks are clear so students know what to do & 2.0 & 27.9 & 52.4 & 17.7 \\
\hline $\begin{array}{l}\text { Teaching approaches allow students to proceed at their } \\
\text { own pace }\end{array}$ & 6.1 & 27.9 & 57.8 & 8.2 \\
\hline The mentor is not interested in student problems & 6.9 & 11.7 & 55.9 & 25.5 \\
\hline $\begin{array}{l}\text { There are opportunities for students to express opinions } \\
\text { in this area }\end{array}$ & 6.1 & 28.6 & 55.1 & 10.2 \\
\hline Students enjoy coming to this area & 2.7 & 13.6 & 54.4 & 29.3 \\
\hline Staff are often punctual & 2.0 & 6.8 & 48.3 & 42.9 \\
\hline $\begin{array}{l}\text { The mentor often thinks of interesting activities for the } \\
\text { student }\end{array}$ & 7.5 & 24.7 & 42.9 & 15.0 \\
\hline $\begin{array}{l}\text { There is little opportunity for the student to pursue } \\
\text { his/her particular interests in this area }\end{array}$ & 6.8 & 30.1 & 51.4 & 11.6 \\
\hline
\end{tabular}




\begin{tabular}{|l|l|l|l|l|}
\hline $\begin{array}{l}\text { The mentor is unfriendly and inconsiderate towards } \\
\text { students }\end{array}$ & 5.4 & 6.1 & 44.9 & 43.5 \\
\hline The mentor dominates briefing sessions/review of \\
progress & 3.4 & 34.2 & 49.3 & 13.0 \\
\hline The practice learning experience is interesting & 1.4 & 6.1 & 49.7 & 42.9 \\
\hline Workload allocation is carefully planned & 6.1 & 29.9 & 50.3 & 13.6 \\
\hline Students seem to do the same tasks in every shift & 19.0 & 46.9 & 29.3 & 4.8 \\
\hline It is the mentor who decides what activities the student & 7.5 & 49.0 & 39.5 & 4.1 \\
\hline completes & & & & \\
\hline
\end{tabular}


Table 5: Mean scores of CLEI Constructs according to Demographic Details

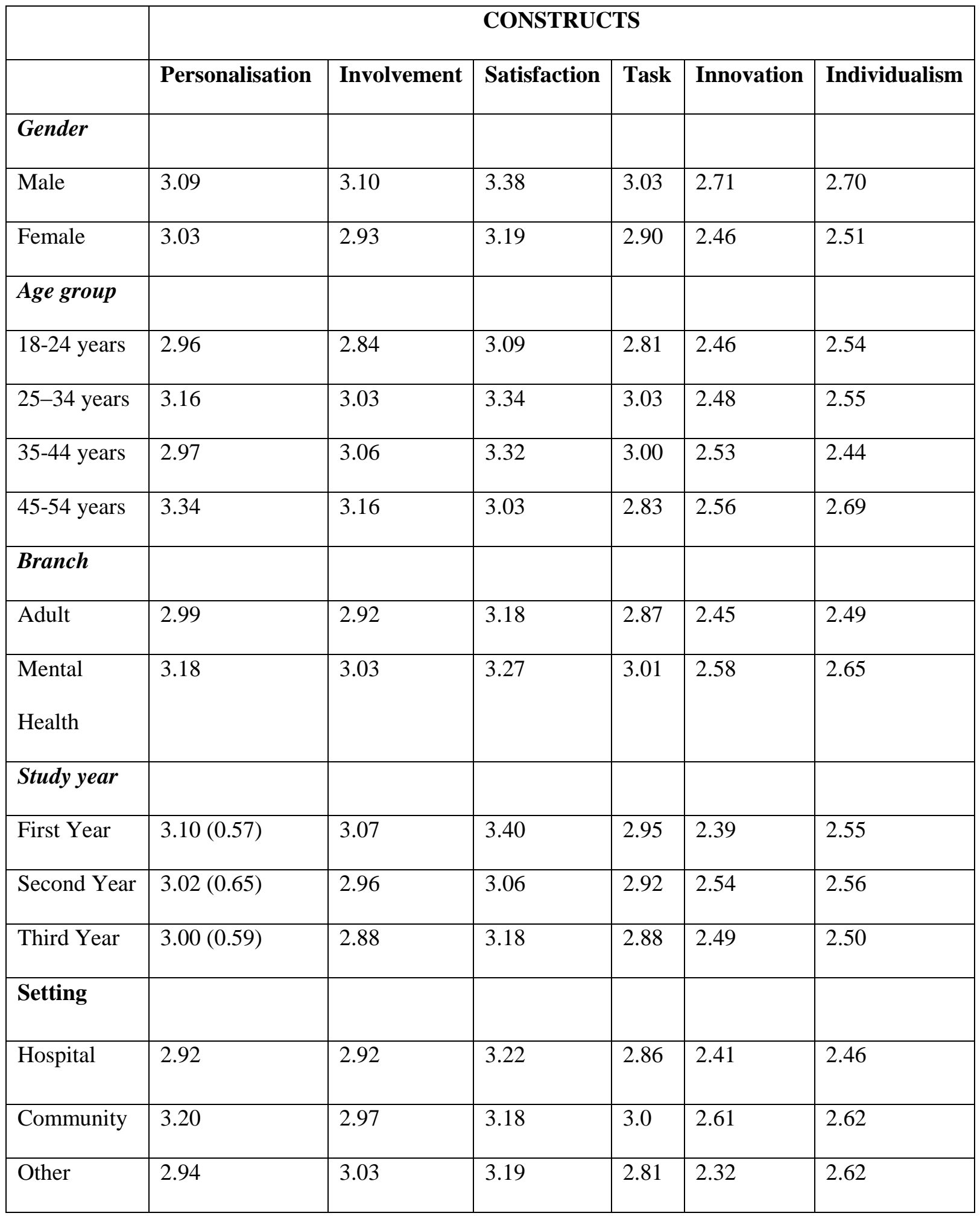


Table 6: Mean scores of items according to clinical placement with statistically significant differences.

\begin{tabular}{|l|l|l|l|l|}
\hline ITEMS & Hospital & Community & Other & Overall \\
\hline Students know exactly what has to be done in the & 2.57 & $2.76(0.64)$ & 2.17 & 2.61 \\
practice learning experience* & $(0.69)$ & & $(1.03)$ & $(0.72)$ \\
\hline The mentor goes out of his/her way to help & 2.72 & $3.13(0.72)$ & 2.75 & 2.88 \\
\hline students* & $(0.82)$ & & $(1.06)$ & $(0.82)$ \\
\hline The mentor thinks up innovative activities for & 2.36 & $2.76(0.82)$ & 2.25 & 2.50 \\
students** & $(0.74)$ & & $(0.97)$ & $(0.81)$ \\
\hline Students have a say in how their shift is spent** & 2.19 & $2.67(0.72)$ & 2.42 & 2.39 \\
\hline The mentor helps the student who is having & $(0.70)$ & & $(0.90)$ & $(0.76)$ \\
\hline difficulty with the work* & 2.78 & $3.11(0.69)$ & 2.45 & 2.88 \\
\hline Students are allowed to negotiate their work load in & 2.35 & $2.75(0.58)$ & 2.50 & 2.51 \\
\hline this area ** & $(0.68)$ & & $(0.80)$ & $(0.70)$ \\
\hline The mentor is not interested in student problems * & 2.92 & $3.18(0.77)$ & 2.55 & 2.99 \\
\hline There are opportunities for students to express & 2.61 & $2.87(0.70)$ & 2.42 & 2.69 \\
\hline
\end{tabular}

$*=$ p. $>0.05 \quad * *=\mathrm{p}>0.01$ 


\section{Highlights}

- The Clinical Environment Learning Inventory (actual) results suggest that preregistration nursing students had different perceptions of their clinical learning experience

- From the six psycho-social aspects of the clinical learning environment that students identify as important satisfaction followed by personalisation received a strong positive rating

- Innovation sub scale gained the lowest mean score.

- Differences between placement groups were not highly significant however statistical difference was reported between age groups and year of study. 